\title{
AMELIORATION OF NECROSIS FORMATION IN GINGIVA BY LICORICE ROOT EXTRACT
}

\author{
SHIVANNI SS, VISHNU PRIYA V*, GAYATHRI R
}

${ }^{1}$ Department of Biochemistry, Saveetha Dental College, Saveetha Institute of Medical and Technical Sciences, Saveetha University, Chennai, Tamil Nadu, India, ${ }^{2}$ Department of Biochemistry Saveetha Dental College, Saveetha Institute of Medical and Technical Sciences, Saveetha University, Tamil Nadu, India. Email: drvishnupriyav@gmail.com

Received: 17 June 2018, Revised and Accepted: 08 June 2018

ABSTRACT

Objective: Gingivitis is a reversible condition associated with a bacterial plaque that resolves in about 1 week after the reinstitution of oral hygiene procedures. If left untreated, may ultimately progress to periodontitis in a subset of individuals. The objective of the study was to evaluate the amelioration of necrosis formation in gingiva by Licorice root extract. The licorice compounds, licoricidin, and licorisoflavan A were the most effective antibacterial substances.

Methods: Licorice root extract was prepared by macerating $50 \mathrm{~g}$ of dry powder with $100 \mathrm{ml}$ of $70 \% \mathrm{w} / \mathrm{v}$ ) ethyl alcohol for a week. Human gingival fibroblasts were obtained from a commercial source and were maintained in serum-free fibroblast medium as recommended by the manufacturer. The cells were treated with licorice root extract $(100 \mu \mathrm{g} / \mathrm{ml})$ and incubated for $48 \mathrm{~h}$. Tumor necrosis factor (TNF) and C-reactive protein (CRP) were estimated.

Result: TNF-alpha levels were raised, and agglutination of CRP was observed in hepatocyte growth factor positive samples whereas after the treatment with licorice root extract the TNF-alpha levels were declined and no agglutination was seen.

Conclusion: TNF and CRP levels are raised during necrosis formation. These levels are decreased when treated with licorice root extract. Thus, licorice root extract causes amelioration of necrosis formation in the gingiva.

Keywords: Amelioration, Gingivitis, Licorice, Periodontitis, Tumor necrosis.

(C) 2018 The Authors. Published by Innovare Academic Sciences Pvt Ltd. This is an open access article under the CC BY license (http://creativecommons. org/licenses/by/4. 0/) DOI: http://dx.doi.org/10.22159/ajpcr.2018.v11i10.26736

\section{INTRODUCTION}

Plants serve as potential storage of various secondary metabolites (phytochemicals). These phytochemicals cover diverse and important biochemical components that serve as a raw material for the development of pharmacologically active natural products. Plants still serve as the base for the existence and development of traditional medicine system for 1000 of years in India [1]. Gingivitis is a reversible condition associated with a bacterial plaque that resolves in about 1 week after the reinstitution of oral hygiene procedures [2,3]. The genus name Glycyrrhiza comes from the ancient Greek word for "sweet root" that was later called as licorice [4]. In Chinese traditional medicine, licorice remains one of the oldest and most commonly prescribed herbs and has been used in the treatment of numerous ailments ranging from tuberculosis to peptic ulcers [5]. Licorice has been found to be effective against fevers, liver ailments, dyspepsia, gastric ulcers, sore throats, asthma, and bronchitis [6]. Matricaria chamomilla (chamomile), Eclipta alba (false daisy), and Glycyrrhiza glabra (licorice) are the well-known traditional medicinal plants used in the treatment of various oral infections. The flowers of chamomile, leaves of false daisy, and roots of licorice were selected for our study due to its various medicinal properties and based on its use in ancient traditional medicines $[7,8]$.

The pharmaceutical importance of licorice lies in their capacity to produce a great variety of secondary metabolites. Depending on the modern studies, the most important bioactive compounds in licorice are triterpenes, flavonoids, and polysaccharides [9]. Inflammation responses with Celsus' four cardinal signs, namely calor, dolor, rubor, and tumor have attracted increasing attention [10]. Inflammation responses play an important role in multiple diseases with a high prevalence among the population, such as hepatitis, lung disease, and Alzheimer's disease. Moreover, they are also centrally related to the pathogenesis of a large number of acute and chronic diseases, such as rheumatoid arthritis, colonic inflammatory response, and periodontitis [11-16]. The conventional therapies for inflammation, including steroids and nonsteroidal anti-inflammatory drugs have shown many side effects and deficiencies [17].

Licorice is an excellent alternative choice, due to the fact that it causes minimal disorders in the physiological functions of the organism, has a non-specific action and exerts a therapeutic action regardless of the direction of the pathological state. Furthermore, it is especially suitable for children, since glycyrrhizin (GC), a compound isolated from licorice, is 50 times sweeter than sugar that makes it much easier for children to accept [18]. The three original plants of licorice are G. uralensis, G. inflata, and G. glabra. They contain many natural active compounds, including more than 20 triterpenes and 300 flavonoids. 73 bioactive compounds and 91 potential targets are identified for this medicinal herb [19]. The large number of metabolites indicated that licorice was an ideal option for obtaining anti-inflammation compounds [3]. Licorice is a perennial herb which possesses sweet taste [20]. Liquorice is the name applied to the extract from roots and shoots of Glycyrrhiza species. It is an herb native to the Mediterranean and certain areas of Asia having varied application in chronic hepatitis, peptic ulcer, and lichen planus. Its usage dates back centuries [21,22].

\section{METHODS}

Preparation of licorice root ethanolic extract

The collected plant materials were shade dried and ground to a coarse powder. The $20 \mathrm{~g}$ of powdered material was weighed and extracted with methanol in a Soxhlet apparatus [8].

\section{Human gingival fibroblasts}

Cells were obtained at passage one and propagated in T-75 flasks. Cells were trypsinized and repeated as needed for experiments. The cells 
were treated with licorice root extract $(100 \mu \mathrm{g} / \mathrm{ml})$ and incubated for $48 \mathrm{~h}$.

\section{Assay of tumor necrosis factor-alpha (TNF- $\alpha$ )}

The wells of microtiter plates were coated with $100 \mu \mathrm{l}$ of cell lines appropriately diluted in carbonate buffer. The plates were kept at $4^{\circ} \mathrm{C}$ overnight and then washed thrice with phosphate buffer saline (pH 7.4) containing $0.05 \%$ Tween 20 and blocked with $3 \%$ BSA in phosphate buffered saline $\left(100 \mu \mathrm{l} /\right.$ well), kept at $37^{\circ} \mathrm{C}$ for $1 \mathrm{hr}$. After washing $100 \mu \mathrm{l}$ of serially diluted antiserum or purified TNF-alpha antibody or the preimmune serum was added and incubated at $37^{\circ} \mathrm{C}$ for $1 \mathrm{hr}$. It was then washed with PBS and Tween 20. The wells were charged with $100 \mu \mathrm{l}$ of anti-rabbit IgG conjugated with horseradish peroxidase. The plates were incubated at $37^{\circ} \mathrm{C}$ for $1 \mathrm{hr}$ and washed. The activity of bound horseradish peroxidase was monitored by addition of $50 \mu$ l of substrate $(1 \mu \mathrm{l}$ of hydrogen peroxide, $0.5 \mathrm{mg}$ OPD in $1 \mathrm{ml}$ of citrate phosphate buffer, $\mathrm{pH} 5.0$ ). After $20 \mathrm{~min}$ in the dark at room temperature, the reaction was arrested by the addition of $50 \mu \mathrm{l}$ of $2 \mathrm{~N}$ sulfuric acid. The intensity of the color was recorded on ELISA reader at $490 \mathrm{~nm}$. The TNF- $\alpha$ concentrations were expressed as picogram $/ \mathrm{ml}$.

\section{C-reactive protein test by agglutination method}

C-reactive protein (CRP) is made by the liver and released into the blood within a few hours after onset of gingivitis. 1 drop of positive control and negative control was placed on separate reaction circle on a glass slide. 1 drop of CRP latex reagent was added to each of the circles. Mixed with separate mixing sticks and the fluid was spread over the entire area of the cell. Visible agglutination was observed.

\section{Statistical analysis}

Results were expressed as mean \pm standard deviation. The statistical analysis was done using one-way ANOVA by SPSS software, and post hoc test was conducted using Dunnett's $\mathrm{t} 3$ test.

\section{RESULTS AND DISCUSSION}

The results of this study show the anti-inflammatory activity of licorice root extract and its role in the amelioration of necrosis formation in human gingival tissues. Fig. 1 show the reduction in the concentration of TNF-alpha, an inflammatory mediator when the tissue is treated with Licorice root extract. Fig. 2 shows the presence of agglutination in $\mathrm{C}$ reactive protein test in non-treated gingivitis tissue and absence of agglutination when the tissue is treated with Licorice root extract. A study by Rui Yang et al. showed that three triterpenes and 13 flavonoids were mainly responsible for the antiinflammatory activity of licorice through a variety of mechanisms, especially downregulation of mediators, such as TNF-alpha, MMPs, $\mathrm{PGE}_{2}$, and oxidative stress on the progression of inflammation-related diseases [20]. A study by Fu et al. found that the anti-inflammatory effects of GC may be attributable to its ability to activate ATP-binding cassette transporter A1. GC might be a useful therapeutic reagent for the treatment of mastitis and other inflammatory diseases [23]. In a study done by Asn et al., the cell toxicity of licorice root extract on normal human gingival fibroblast cells was tested using a methyl thiazolyl tetrazolium assay. These results suggest that DG-LRE can be used in developing oral hygiene products, such as dentifrice to prevent human dental caries [24]. The results of Cho et al. indicate that HEGU, which contains licoricidin, is a potent anti-metastatic agent, which can markedly inhibit the metastatic and invasive capacity of malignant prostate cancer cells $[25,26]$ which support the protection against HGF by licorice root extract treatment.

\section{CONCLUSION}

TNF-alpha and CRP levels are raised during necrosis formation and these levels were decreased when treated with licorice root extract treatment. Thus, licorice root extract causes amelioration of necrosis formation in gingiva.

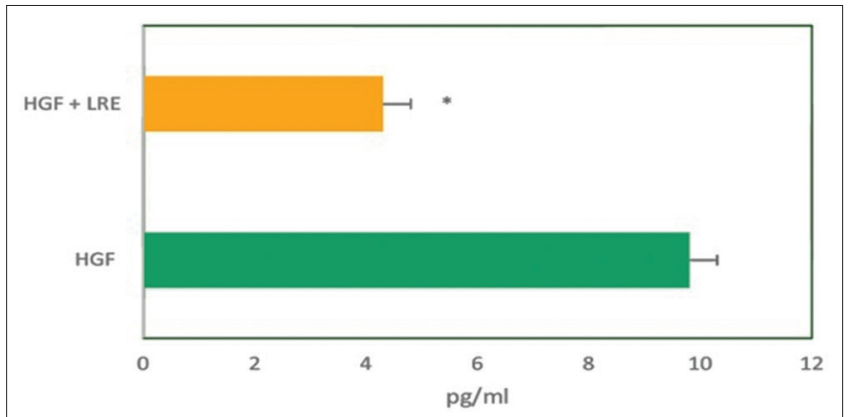

Fig. 1: Concentration of tumor necrosis factor-alpha before and after addition of licorice root extract. Results are expressed as mean \pm standard deviation $(n=6) . * p<0.001$ significantly different as compared with hepatocyte growth factor positive samples without licorice treatment

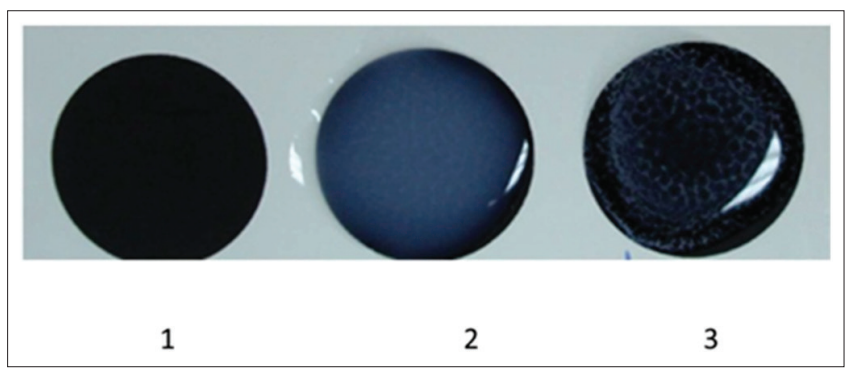

Fig 2: C-reactive protein (CRP) agglutination test results in hepatocyte growth factor (HGF) positive samples and after the

licorice root extract treatment. Sample 1 - CRP negative for normal cell medium; Sample 2 - No agglutination seen for licorice root extract treated sample; and Sample 3 - CRP positive for HGF

\section{CONFLICTS OF INTEREST}

The authors declare that there are no conflicts of interest regarding the publication of this article.

\section{AUTHOR'S CONTRIBUTION}

Shivani has performed the review of literature, biochemical analysis, compilation of paper. Dr. Vishnu Priya V has majorly performed the literature survey, research proposal, biochemical analysis, compilation of paper. Gayathri R has provided the extract preparation, statistical analysis and sample collection.

\section{REFERENCES}

1. Saranya VT. Phytochemical analysis and in vitro studies on antibacterial, antioxidant and anti-inflammatory activities using Casuarina equisetifolia bark extracts. Int J Pharm Pharm Sci 2018;10:118-25.

2. Seymour RA, Ellis JS, Thomson JM, Monkman S, Idle JR. Amlodipineinduced gingival overgrowth. J Clin Periodontol 1994;21:281-3.

3. Brown RS, Sein P, Corio R, Bottomley WK. Nitrendipine induced gingival hyperplasia. First case report. Oral Surg Oral Med Oral Pathol 1990;70:593-6.

4. Isbrucker RA, Burdock GA. Risk and safety assessment on the consumption of licorice root (Glycyrrhiza sp.), its extract and powder as a food ingredient, with emphasis on the pharmacology and toxicology of glycyrrhizin. Regul Toxicol Pharmacol 2006;46:167-92.

5. Schulz V, Hansel R, Tyler VE. Rational Phytotherapy. A Physicians' Guide to Herbal Medicine. Berlin, Germany: Springer-Verlag; 1998. p. 160-87.

6. Huang KC. The pharmacology of Chinese herbs. Boca Raton, Fl: CRC Press, Inc.; 1993. p. 275-8.

7. Anon. Glycyrrhiza glabra. Altern Med Rev 2005;10:230-7.

8. Lavanya J. Antioxidant and antimicrobial activity of selected medicinal plants against human oral pathogens. Int J Pharm Pharm Sci 2016;8:71-8 
9. Seki H, Sawai S, Ohyama K, Mizutani M, Ohnishi T, Sudo H, et al. Triterpene functional genomics in licorice for identification of cyp72a154 involved in the biosynthesis of glycyrrhizin. Plant Cell Online 2011;23:4112-23.

10. Fullerton JN, Gilroy DW. Resolution of inflammation: A new therapeutic frontier. Nat Rev Drug Discov 2016;15:551-67.

11. Matsuzaki K, Murata M, Yoshida K, Sekimoto G, Uemura Y, Sakaida N, et al. Chronic inflammation associated with hepatitis $\mathrm{C}$ virus infection perturbs hepatic transforming growth factor beta signaling, promoting cirrhosis and hepatocellular carcinoma. Hepatology 2007;46:48-57.

12. Yang H, Ko HJ, Yang JY, Kim JJ, Seo SU, Park SG, et al. Interleukin-1 promotes coagulation, which is necessary for protective immunity in the lung against Streptococcus pneumoniae infection. J Infect Dis 2013;207:50-60.

13. Jayaraman A, Lent-Schochet D, Pike CJ. Diet-induced obesity and low testosterone increase neuroinflammation and impair neural function. J Neuroinflammation 2014;11:162.

14. Yang CL, Or TC, Ho MH, Lau AS. Scientific basis of botanical medicine as alternative remedies for rheumatoid arthritis. Clin Rev Allergy Immunol 2013;44:284-300.

15. Takhshid MA, Mehrabani D, Ai J. The healing effect of licorice extract in acetic acid-induced ulcerative colitis in rat model. Comp Clin Pathol 2012;21:1139-44.

16. Farhad SZ, Aminzadeh A, Mafi M, Barekatain M, Naghney M, Ghafari MR. The effect of adjunctive low-dose doxycycline and licorice therapy on gingival crevicular fluid matrix metalloproteinase- 8 levels in chronic periodontitis. Dent Res J 2013;10:624-9.

17. Sostres C, Gargallo CJ, Arroyo MT, Lanas A. Adverse effects of non-steroidal anti-inflammatory drugs (NSAIDs, aspirin and coxibs) on upper gastrointestinal tract. Best Pract Res Clin Gastroenterol
2010;24:121-32.

18. Liu H, Wang J, Zhou W, Wang Y, Yang L. Systems approaches and polypharmacology for drug discovery from herbal medicines: An example using licorice. J Ethnopharmacol 2013;146:773-93.

19. Li S, Zhu JH, Cao LP, Sun Q, Liu HD, Li WD, et al. Growth inhibitory in vitro effects of glycyrrhizic acid in U251 glioblastoma cell line. Neurol Sci 2014;35:1115-20.

20. Geetha RV, Roy A. In vitro evaluation of anti-bacterial activity of ethanolic root extract of Glycyrrhiza glabra on oral microbes. Intl J Drug Dev Res 2012;4:26-30.

21. Jyotsna S, Gargi S, Victor S. Assessing the effectiveness of liquorice root extract lollipop in reducing the $S$. mutans. Int J Pharm Bio Sci 2015;6:935-9

22. Rui Y, Bo-Chuan Y, Yong-Sheng M, Shanzhou Y. The antiinflammatory activity of licorice, a widely used Chinese herb. Pharm Biol 2017;55:5-18

23. Fu Y, Zhou E, Wei Z, Liang D, Wang W, Wang T, et al. Glycyrrhizin inhibits the inflammatory response in mouse mammary epithelial cells and a mouse mastitis model. FEBS J 2014;281:2543-57.

24. Ahn SJ, Cho EJ, Kim HJ, Park SN, Lim YK, Kook JK, et al. The antimicrobial effects of deglycyrrhizinated licorice root extract on Streptococcus mutans UA159 in both planktonic and biofilm cultures. Anaerobe 2012;18:590-6.

25. Bhattacharjee S, Bhattacharjee A, Majumder S, Majumdar SB, Majumdar S. Glycyrrhizic acid suppresses cox-2-mediated antiinflammatory responses during Leishmania donovani infection. J Antimicrob Chemother 2012;67:1905-14.

26. Cho HJ, Lim SS, Lee YS, Kim JS, Lee CH, Kwon DY, et al. Hexane/ ethanol extract of licorice exerts potent anti-inflammatory effects in murine macrophages and in mouse skin. Food Chem 2010;121:959-96. 